\title{
Advances in the Treatment of Relapsing - Remitting Multiple Sclerosis
}

\author{
Radu Tanasescu ${ }^{1,2}$, Carolina Ionete ${ }^{3}$, I-Jun Chou ${ }^{1,4}$, Cris S. Constantinescu ${ }^{1}$
}

This article reviews and discusses the approved and emerging therapies for multiple sclerosis (MS). MS is a chronic and disabling immune-mediated disease of the central nervous system (CNS) that affects mainly young adults. MS imposes a huge economic burden on healthcare systems and the society. Although the last 20 years have brought a continuous expansion in therapeutic options, there are still unmet needs in MS management. Available MS drugs have varying degrees of efficacy in reducing relapse risk. The long-term term effects of these treatments are incompletely known. New therapies, along with variations of currently available treatments, may prove more effective and tolerable than the available drugs. Treatments for MS differ with respect to the mode of administration, tolerability and likelihood of treatment adherence, side effects, and risk of major toxicity. The armamentarium of approved disease-modifying therapies in MS and those in development include: (1) the first approved, moderately effective, injectable interferon- $\beta$ and glatiramer acetate; (2) oral drugs (fingolimod, laquinimod, teriflunomide, dimethyl fumarate); (3) monoclonal antibodies (rituximab, ocrelizumab, ofatumumab, daclizumab, alemtuzumab); and (4) immunosuppressive agents (e.g. mitoxantrone). The place of each drug in the therapeutic algorithm is dependent on its specific risk-benefit profile. Patients' clinical and paraclinical phenotypes and biomarker profile may help to elucidate disease subtypes and response to therapy in the future, thus allowing treatment individualization. (Biomed J 2014;37:41-49)

\section{Key words: disease-modifying treatments, monoclonal antibodies, multiple sclerosis, oral drugs}

$\mathrm{M}$ ultiple sclerosis (MS) is a chronic, immune-mediated disease of the central nervous system (CNS). Pathologic hallmarks of MS lesions are inflammation, demyelination, axonal degeneration, neuronal loss, and gliosis. ${ }^{[1,2]}$

MS is the most common neurological non-traumatic cause of disability in young people in the western world. MS initially presents in most patients as a relapsing-remitting condition (RRMS), but the majority of RRMS individuals develop a secondary progressive course (SPMS) later. ${ }^{[3]}$ In fewer cases, the disease progresses from the beginning without superimposed relapses [primary progressive MS (PPMS)] or with rare superimposed relapses [progressive relapsing MS (PRMS)]. ${ }^{[4]}$

The clinical signs in MS can occur in isolation or in combination, and can include motor and sensory deficits, partial or complete visual loss, diplopia, impaired coor- dination, and gait dysfunction. The diagnosis specifically integrates magnetic resonance imaging (MRI) with clinical attacks and paraclinical methods, and implies the dissemination of inflammatory activity in time and space. ${ }^{[5]}$

MS treatments tackle separately the acute exacerbations and their prevention. Pharmacological management of relapses involves the use of corticosteroids, while approved long-term treatments [disease-modifying treatments (DMTs)] aim to decrease the clinical relapse rate and concomitant inflammation within the CNS.

MS therapeutic landscape is changing rapidly. After several years in which first-line DMTs - glatiramer acetate (GA) and interferon $\beta$ (IFN $\beta$ ) - constituted the principal treatment options, a variety of new agents for MS treatment are now approved by regulatory authorities or in phase II and III clinical trials. ${ }^{[6]}$ In 2010, fingolimod, the first oral agent,

From the ${ }^{1}$ Academic Clinical Neurology, Division of Clinical Neuroscience, School of Medicine, University of Nottingham, Nottingham, England, UK; ${ }^{2}$ Department of Neurology, Neurosurgery and Psychiatry, Carol Davila University of Medicine and Pharmacy, Colentina Hospital, Bucharest, Romania; ${ }^{3}$ University of Massachusetts, Multiple Sclerosis Centre, Worcester, MA, USA; ${ }^{4}$ Division of Pediatric General Medicine, Chang Gung Children's Hospital at Linkou, Chang Gung University College of Medicine, Taoyuan, Taiwan Received: Dec. 02, 2013; Accepted: Mar. 21, 2014

Correspondence to: Dr. Radu Tanasescu, Academic Clinical Neurology, Division of Clinical Neuroscience, School of Medicine, University of Nottingham, UK. C Floor, South Block, QMC, Nottingham NG7 2UH, UK. Tel: 44-115-8754597; Fax: 44-115-9709738; E-mail: radu. tanasescu@nottingham.ac.uk

DOI: $10.4103 / 2319-4170.130440$ 
was approved by the Food and Drug Administration (FDA) in the US. Fingolimod was proven superior in RRMS to placebo and once weekly IFN $\beta{ }^{[7,8]}$ Other oral agents have been recently been approved, are currently in phase III trials, or will be submitted to the regulatory agencies for approval. Moreover, several monoclonal antibodies are also in late stage development for MS.$^{[6]}$ The purpose of this paper is to provide a brief review of the actual and changing treatment landscape in RRMS.

\section{Injectable drugs approved for MS}

IFN $\beta$ and GA have relatively comparable efficacy, reducing the relapse rate (RR) by approximately $30 \% .{ }^{[9]}$ Three IFN $\beta$ dr ugs are in widespread use as first-line DMTs for relapsing MS (RRMS and SPMS) with relapses: IFN- $\beta 1 \mathrm{~b}[\mathrm{Be}-$ taseron/Betaferon ${ }^{\circledR}$, Extavia $^{\circledR}$, requiring subcutaneous (s.c.) administration], IFN- $\beta 1 \mathrm{a}$ (Avonex ${ }^{\circledR}$, given intramuscularly), and Rebif $^{\circledast}$ (s.c.). They are also approved in some countries for clinically isolated syndrome (CIS).$^{[10,11]}$ Each of the three IFN $\beta$ drugs was licensed following single multicenter, double-blind, placebo-controlled, phase III trials. ${ }^{[12-14]}$ IFN $\beta$ is well tolerated. Side effects include flu-like symptoms, increase in liver enzyme activities, and injection-site reactions.

GA (Copaxone ${ }^{\circledR}$ ) is a four amino acid synthetic copolymer based on the composition of myelin basic protein. ${ }^{[15]}$ GA is approved for RRMS and, in some countries, for CIS patients. GA has positive effects on regulatory T cells (Treg), modulates B cell cytokine secretion, and mediates a $\mathrm{T}$ cell shift toward an anti-inflammatory $\mathrm{T}$ helper (Th)-2 phenotype ${ }^{[16]} \mathrm{GA}$ was approved after a single multicenter, randomized, placebo-controlled trial. ${ }^{[17]}$ A subsequent multicenter placebo-controlled trial showed positive GA effects using MRI activity as a primary outcome measure.$^{[18]} \mathrm{GA}$ is generally safe. Side effects include local injection site reactions and post-injection reactions which occur in about $15 \%$ of patients. ${ }^{[19]}$

Both IFN and GA require regular, long-term, self-injection administration. Issues of tolerance and adherence to treatment may reduce the likelihood of achieving durable treatment efficacy ${ }^{[9]}$ Approved second-line therapies such as the humanized antibody natalizumab and the cytostatic agent mitoxantrone are more effective and, therefore, reserved for highly active MS. ${ }^{[20]}$ They are administered parenterally and are associated with potentially severe side effects [e.g. progressive multifocal leukoencephalopathy (PML) for natalizumab, cardiotoxicity and acute leukemia for mitoxantrone].

Natalizumab is a humanized recombinant monoclonal antibody against $\alpha 4$-integrin. It diminishes leukocyte migration from the peripheral blood into the CNS by preventing its binding via $\alpha 4$-integrin to the ligand vascular cell adhesion molecule (VCAM) found on endothelial surfaces. ${ }^{[15]}$ This blocks the adhesion and subsequent migration of lympho- cytes across the blood-brain barrier (BBB), attenuating CNS inflammation.

In the pivotal placebo-controlled phase III trial Natalizumab Safety and Efficacy in Relapsing-Remitting MS (AFFIRM), natalizumab [administered $300 \mathrm{mg}$ intravenously (i.v.) monthly] was found to reduce RR by $68 \%$ and sustained progression of disability at 2 years by $42 \%$. $^{[21]}$ MRI activity was reduced by $92 \%$ in the natalizumab-treated group $(p<0.001){ }^{[22]}$

Following two cases of PML in the Safety and Efficacy of Natalizumab in Combination with Avonex ${ }^{\circledR}$ [IFN $\left.\beta-1 \mathrm{a}\right]$ in Patients with Relapsing-Remitting Ms (SENTINEL) trial, ${ }^{[23]}$ the drug was voluntarily suspended in 2005 by the manufacturer. ${ }^{[15]}$ Natalizumab was reintroduced in June 2006 with revised labeling and after introduction of risk management programs. ${ }^{[15]}$ Recently, PML risk stratification for MS patients on natalizumab became possible by assessing anti- JC virus (JCV) antibody status reflecting infection with JCV. ${ }^{[24,25]}$ Duration of treatment and prior immunosuppressant use were determined to be correlated with a higher risk of PML. As of November 2013, the incidence of PML was 3.4/1000 patients (95\% CI 3.08-3.74). 77\% patients are alive with varying levels of disability. The availability of the JCV testing is allowing further risk stratification during natalizumab administration. ${ }^{[15]}$

Mitoxantrone (Novantrone), an anthracenedione cytotoxic agent, is an antineoplastic cytotoxic agent that inhibits type II topoisomerase and disrupts DNA synthesis. Mitoxantrone can cross the disrupted BBB in MS and in vitro evidence suggests it can induce microglial death. ${ }^{[26]}$ Mitoxantrone was approved in 2000 for rapidly worsening RRMS or SPMS by the FDA and has proven its efficacy in several trials. ${ }^{[27]}$ Mitoxantrone is administered at doses of $12 \mathrm{mg} / \mathrm{m}^{2}$ monthly or every 3 months i.v.; however, the cumulative dose is limited, and cardiologic and hematologic monitoring is required. ${ }^{[27,28]}$ Well-known side effects of Mitoxantrone, including nausea, alopecia, increased risk of infection and infertility, and post-marketing reports of cardiotoxicity, ${ }^{[29]}$ resulted in a 2005 FDA "black box" warning, and an American Academy of Neurology review found that systolic dysfunction occurred in $12 \%$ of MS patients treated with mitoxantrone, congestive heart failure in $0.4 \%$, and treatment-related acute leukemia (TRL) in $0.8 \% .{ }^{[30]} \mathrm{A}$ 5 -year phase 4 study [the Registry to Evaluate Novantrone Effects in Worsening Multiple Sclerosis (RENEW)] of 509 patients in 46 US centers reported a $2 \%$ incidence for heart failure and $0.6 \%$ for TRL. ${ }^{[31]}$

\section{Approved and emerging oral drugs for MS}

Since injectable drugs raise the issues of adherence and tolerance, oral therapies do offer a step forward in convenience. Fingolimod (Gilenya) is the first in a new class of 
therapeutic compounds known as sphingosine 1-phosphate receptor (S1PR) modulators. Fingolimod represents a milestone in the treatment of RRMS, being the first approved oral therapy. It is approved in a number of countries for the treatment of RRMS in patients with high disease activity despite treatment with IFN $\beta$ or rapidly evolving RRMS. Fingolimod is an innovative drug developed from fungal metabolite myriocin and was initially studied in organ transplantation. It is a prodrug phosphorylated in vivo to fingolimod phosphate (fingolimod-P) by sphingosine kinase-2 (Sphk2). ${ }^{[32,33]}$ Fingolimod-P is a high-affinity, non-selective agonist of four of the five known $\mathrm{G}$ protein-coupled sphingosine-phosphate receptors (S1PRs 1, 3, 4, 5) and modulates their expression on lymphocytes and cells in the CNS and cardiovascular system. ${ }^{[32]}$ S1PRs have significant functions in the immune system and CNS, and S1P signaling is important in neuroinflammatory processes. ${ }^{[34]}$ The main effect of fingolimod on the immune system is the down-modulation of S1P1 receptors on lymphocytes, preventing their egress from lymph nodes. This affects selectively naïve and central memory $\mathrm{T}$ cells and $\mathrm{B}$ cells, but spares effector memory $\mathrm{T}$ cells and, therefore, preserves their key immune functions $^{[35]}$ Therefore, fingolimod acts through redistribution of lymphocytes to the lymphoid tissues rather than lymphocyte destruction, as seen with cytotoxic agents. ${ }^{[36]}$ S1PRs are also found on virtually all neural cell lineages, and while there are in vitro data suggesting that fingolimod could affect oligodendrocyte precursor cell survival, recruitment, and activation, and attenuate astrogliosis, the evidence needs supporting in vivo data.

The approval of fingolimod in MS was based on the largest phase III clinical trial program in MS at the time of submission. ${ }^{[37]}$ Clinical efficacy and safety of fingolimod in RRMS have been evaluated in one phase II and two double-blind, randomized phase III trials (Efficacy and Safety of Fingolimod in Patients With Relapsing-Remitting Multiple Sclerosis, FREEDOMS; and Efficacy and Safety of Fingolimod in Patients With Relapsing-Remitting Multiple Sclerosis With Optional Extension Phase, TRANSFORMS $){ }^{[8,38,39]}$ The FREEDOMS trial included 1272 RRMS patients for 24 months, randomized to either 0.5 or $1.25 \mathrm{mg}$ fingolimod or placebo. ${ }^{[8]}$ There was a significant reduction in the annualized RR $(p<0.001)$ for both doses. Fingolimod reduced the risk of disability progression over 24 months and met the MRI endpoints $(p<0.001) .{ }^{[8]}$ The TRANSFORMS study compared fingolimod to intramuscular IFN- $\beta 1$ a once weekly. ${ }^{[39]} \mathrm{A}$ total of 1292 patients with active RRMS with an Expanded Disability Status Scale (EDSS) score between 0 and 5.5 were included. Average disease duration was 7.4 years, and the patients had a mean EDSS of 2.2. The majority of patients had previous DMTs, mostly IFN $\beta$ or GA. The proportion of relapse-free patients was signifi- cantly higher in both fingolimod-treated groups (fingolimod $0.5 \mathrm{mg}$ : 82.6\%; fingolimod $1.25 \mathrm{mg}$ : $79.8 \%$; IFN- $\beta 1 \mathrm{a}$ : $69.3 \%$ ), as also the MRI outcomes (less Gd+ lesions, new or enlarged T2 lesions, and brain atrophy). TRANSFORMS study patients who were treated with IFN- $\beta 1$ a were randomly assigned to receive $0.5 \mathrm{mg}$ or $1.25 \mathrm{mg}$ of fingolimod in an extension of the trial. ${ }^{[40]}$ Clinical and MRI outcomes improved in the group that switched from IFN- $\beta 1$ a to fingolimod, whilst patients receiving continuous fingolimod had unchanged benefits. ${ }^{[40]}$ Because initial data suggested that fingolimod may have an effect on nerve repair, a trial in PPMS (INFORMS) has been launched. ${ }^{[41]}$ In INFORMS, the effects of fingolimod ( 0.5 or $1.25 \mathrm{mg}$ tablets taken daily for 3 years) on delaying disability progression are compared to placebo in 654 people with PPMS. INFORMS is due to end in 2014.

In fingolimod studies, herpes infection and skin cancers were more common in the treated groups; other adverse events included mild hypertension, elevated values of liver enzymes, and macular edema. ${ }^{[8,39]}$ Cardiac adverse events (bradycardia mainly within $6 \mathrm{~h}$ of first administration and first- and second-degree atrioventricular conduction block) are a consequence of modulation of S1PR1 and S1PR3 on atrial myocytes. ${ }^{[34]}$ The European Medicines Agency (EMA) and the FDA reviewed the license for fingolimod after patients started on the drug had serious cardiovascular events ${ }^{[2,43]}$ and recommended that the drug should not be prescribed to patients with pre-existing cardiac or cerebrovascular disease and a closer clinical and ECG monitoring of patients was advised after the first administration.

Teriflunomide (Aubagio) is the metabolite of leflunomide, which has been approved for mild to moderate rheumatoid arthritis. ${ }^{[4]]}$ The pharmacokinetics of both drugs are similar. ${ }^{[4]}$ Teriflunomide is administered once daily and the oral bioavailability is almost $100 \%$. It inhibits dihydroorotate dehydrogenase (DHODH), the rate-limiting mitochondrial enzyme in de novo pyrimidine synthesis. ${ }^{[44]}$ A salvage pathway independent of DHODH suffices for resting lymphocytes, but fast-proliferating cells such as activated lymphocytes are dependent on de novo synthesis and are a selective target of teriflunomide. ${ }^{[44]}$ Other actions include impairing the migratory capacity of $\mathrm{T}$ cells, biasing the differentiation of naive $\mathrm{T}$ cells toward a Th2 phenotype, decreasing $\mathrm{T}$ cell-dependent antibody production, and effects on B cells. ${ }^{[15]}$

The first randomized phase II study of teriflunomide versus placebo in RRMS showed a significant suppression of more than $61 \%$ of MRI activity for teriflunomide. ${ }^{[45]}$ Two phase II trials that investigated the value of teriflunomide as an adjunctive treatment to either IFN $\beta$ (now in phase III - TERACLES) or GA for 24 weeks have also 
shown positive clinical and radiological results. ${ }^{[46,47]}$ The Teriflunomide Multiple Sclerosis Oral (TEMSO) trial was a phase III trial that randomized 1088 RRMS to placebo, 7 , or $14 \mathrm{mg}$ teriflunomide once daily for 108 weeks. The annualized relapse rate (ARR) was significantly reduced by teriflunomide ( 0.54 for placebo vs. 0.37 for either 7 or $14 \mathrm{mg}$ teriflunomide, representing a $31 \%$ relative risk reduction) and the positive MRI results of the phase II studies were replicated with a magnitude similar to the currently available first-line DMTs. ${ }^{[48]}$

Two other phase III studies (TENERE and TOWER) showed similar effects between teriflunomide 7 and $14 \mathrm{mg}$ and IFN $\beta$, and a $36.3 \%$ reduction in $\mathrm{RR}$ and a $31.5 \%$ reduction in the risk of 12-week sustained accumulation of disability for $14 \mathrm{mg}$ teriflunomide when compared with placebo. ${ }^{[44]}$ Currently, the efficacy and safety of 2-year treatment with teriflunomide ( 7 and $14 \mathrm{mg}$ ) compared to placebo in CIS patients is evaluated in being a phase III trial (TOPIC) expected to complete in 2015. ${ }^{[44]}$ Teriflunomide has been approved by the FDA in 2012 and is currently under review by the EMA. Common adverse events with teriflunomide include abdominal pain, diarrhea, dyspepsia, nausea, vomiting and oral ulcers, elevated liver enzymes, alopecia, skin rashes, and hypertension. ${ }^{[44]}$ Cases of PML have been described in patients with a previous history of immunosuppression treated with leflunomide. ${ }^{[44,49]}$ Teriflunomide is approved by EMA $^{[50]}$ and FDA. ${ }^{[51]}$

BG12 (dimethyl fumarate) is an ester of dimethyl fumaric acid, already licensed as a second-line agent in severe psoriasis. ${ }^{[4]}$ BG12 is almost completely absorbed in the small intestine and is hydrolyzed to the active metabolite monomethyl fumarate. The exact mode of action of BG12 is not completely understood. It may polarize the immune system toward a Th2 phenotype, increase the production of the anti-inflammatory cytokines interleukin (IL)-10 and IL-1 receptor antagonist (IL-1RA), attenuate lipopolysaccharide-induced production of tumor necrosis factor-alpha (TNF $\alpha$ ), IL-1 $\beta$, IL-6, and nitric oxide (NO). ${ }^{[15]}$ BG12 may have neuroprotective effects via activation of the NF-E2-related factor 2 (Nrf-2) antioxidant pathway. ${ }^{[52]}$

A 24-week double-blind phase II study randomized 257 RRMS patients into four groups to receive 120 or 360 or $720 \mathrm{mg}$ BG12 daily or placebo. The dose of $720 \mathrm{mg}$ daily resulted in $70 \%$ reduction of gadolinium-enhancing lesions $(\mathrm{Gd}+) .{ }^{[53,54]}$ In a first phase III trial (DEFINE), daily dose of $480 \mathrm{mg}$ and $720 \mathrm{mg}$ of BG12 showed superiority to placebo by reducing the proportion of patients who relapsed within 2 years $(p<0.0001)$ and by reducing the annualized RR (53 and $48 \%$ for the $480 \mathrm{mg}$ and $720 \mathrm{mg}$ daily dose, respectively) and the MRI outcomes. ${ }^{[55]} \mathrm{A}$ second phase III trial (CONFIRM) compared BG12 with GA and placebo. The study was not sufficiently powered to detect a difference between BG12 and GA. There was a significant reduction in ARR in all active arms of the trial at 2 years, but was more

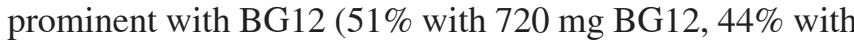
$480 \mathrm{mg} \mathrm{BG} 12$, and $29 \%$ with GA). ${ }^{[56]}$

Adverse events occurring more frequently with BG12 include gastrointestinal symptoms, and flushing typically occurring within $30 \mathrm{~min}$ of administration. ${ }^{[56]}$ Adverse events and drug discontinuation were more frequent at treatment initiation and then substantially subsided ${ }^{[56]}$ Proteinuria was the most commonly reported renal event in DEFINE trial (9\% in the $480 \mathrm{mg}$ daily BG12 group, $12 \%$ in the $720 \mathrm{mg}$ daily BG12 group, and $8 \%$ in the placebo group). ${ }^{[5]}$ BG12 was approved by the FDA in March 2013. ${ }^{[57]}$ In February 2014, a license was granted by the EMA. ${ }^{[58]}$

Laquinimod is a novel oral immunomodulator that has high oral availability and is distributed to the CNS. It has both anti-inflammatory and neuroprotective effects, but is not immunosuppressive. ${ }^{[59,60]}$ Laquinimod is metabolized by the cytochrome P450 enzyme and is inhibited by other substrates such as ketoconazole. ${ }^{[60]}$ Laquinimod inhibits leukocyte migration into the CNS by reducing Very Late Antigen-4 (VLA-4) responsiveness to the chemokine (C-C motif) ligand 21 (CCL21) produced by $\mathrm{T}$ cells and endothelial cells in the inflamed CNS, shifts cytokine profile to a Th2-Th3 phenotype, decreases the entry of autoreactive $\mathrm{T}$ cells into the CNS, and suppresses major histocompatibility complex (MHC) class II antigen presentation. ${ }^{[15]}$ Studies in the animal model of MS experimental autoimmune encephalomyelitis (EAE) suggest the neuroprotective effects of laquinimod exerted by secretion of brain-derived neurotrophic factor. ${ }^{[61]}$

A first phase II study compared 0.1 and $0.3 \mathrm{mg}$ oral laquinimod to placebo in 209 RRMS patients over 24 weeks. Laquinimod produced a significant reduction of $44 \%$ in the cumulative number of MRI active lesions versus placebo, but there were no differences in relapses and disability ${ }^{[62]}$ (the study was not powered to detect these). A second phase II study compared 0.3 and $0.6 \mathrm{mg}$ oral laquinimod to placebo in 306 RRMS patients or placebo. ${ }^{[63]}$ Treatment with $0.6 \mathrm{mg}$ laquinimod led to a $40 \%$ reduction in new enhancing MRI lesions, $44 \%$ reduction in cumulative number of $\mathrm{T} 2$ lesions, and $51 \%$ reduction in new $\mathrm{T}$ 1-hypointense lesions, but no significant change in the RR or disability progression. ${ }^{[63]}$

The first phase III trial ALLEGRO study showed a $23 \%$ reduction in the annualized $\mathrm{RR}$, used as the primary endpoint, compared to placebo ( 0.30 for laquinimod vs. 0.39 for placebo; $p=0.002) .{ }^{[64,65]}$ However, a second phase III trial (BRAVO) which compared $0.6 \mathrm{mg}$ laquinimod with placebo and IFN- $\beta 1$ a failed to reach its primary endpoint and showed no reduction in annualized RR for fingolimod when compared to placebo. ${ }^{[15]}$ This led the manufacturer (Teva Pharmaceuticals) to delay requesting for FDA approval 
and conduct more studies. Currently, laquinimod is being reviewed by the EMA. ${ }^{[15]}$

Laquinimod is overall safe. In the ALLEGRO study, the three most common adverse events in the laquinimod group were abdominal pain, back pain, cough, and elevated liver enzymes. Further data on laquinimod's safety will be provided by the ongoing open-label extension of ALLEGRO. ${ }^{[15]}$

\section{Monoclonal antibodies}

Alemtuzumab (Campath-1H) is a humanized monoclonal antibody targeting CD52 expressed on lymphocytes, natural killer (NK) cells, monocytes, and some granulocytes. ${ }^{[66]}$ It produces antibody-dependent cellular cytotoxicity with rapid and profound lymphopenia lasting for years. ${ }^{[67]}$

CAMMS223 was a randomized phase II trial comparing alemtuzumab with IFN- $\beta 1 \mathrm{a}$ in the treatment of early RRMS ${ }^{[68]}$ At the 36-month follow-up, both doses of $12 \mathrm{mg}$ and $24 \mathrm{mg}$ i.v. alemtuzumab reduced the risk of sustained disability by $71 \%$ and the rate of relapse by $74 \%$ compared to IFN- $\beta 1 a{ }^{[68]}$ A significantly greater number of patients experienced a sustained improvement in disability with alemtuzumab than with IFN $\beta$ after 5 years of follow-up. ${ }^{[69,70]}$

The first phase III trial compared alemtuzumab with Rebif (CARE-MS 1). ${ }^{[71]}$ Alemtuzumab reduced the relapse rate by $55 \%$ compared to Rebif $(p<0.0001)$, but failed to replicate the phase II results of preventing disability progression. The second phase III trial (CARE-MS 2) recruited RRMS patients who had experienced a relapse on previous treatments. Alemtuzumab reduced the RR by $49 \%(p<0.0001)$. Regarding disability reduction, alemtuzumab induced at 6 months a $42 \%$ reduction in the risk of sustained disability accumulation, in comparison to Rebif $(p=0.0084) .^{[15]}$

Infusion reactions (rash, flushing, headache, pyrexia, nausea) were very frequent with alemtuzumab $(98.6 \%$ in CAMMS223). ${ }^{[15]}$ Infections (upper respiratory tract, urinary tract and herpetic infections) were more common in the alemtuzumab groups than in control groups. A protocol amendment introduced prophylactic oral acyclovir during and for 28 days after alemtuzumab infusion, which decreased the frequency of herpetic infections in CARE-MS 1 and CARE-MS 2. ${ }^{[15]}$ Cancers were reported in all trials in the alemtuzumab treated groups (three in CAMMS223, two in CARE-MS 1, two in CARE-MS 2). The major safety concern in alemtuzumab treated groups was represented by autoimmune conditions. It was suggested that IL-21 represents a marker to identify patients at risk for autoimmunity. ${ }^{[72]}$ Idiopathic thrombocytopenic purpura (ITP) developed in six patients in CAMMS223 (one of whom died), in three patients in CARE-MS 1, and in seven patients in CARE-MS $2 \cdot{ }^{[15]}$ Other autoimmune-associated conditions were reported, with thyroid disorders being the most common. ${ }^{[3,69]}$

Rituximab is licensed for the treatment of non-Hodgkin lymphoma, systemic lupus erythematous (SLE), and rheumatoid arthritis refractory to anti-TNF therapies. Rituximab is a chimeric monoclonal antibody that targets CD20 expressed by pre-B cells and mature B cells (but not by plasma cells or hematopoietic stem precursor cells). CD20 functions as a calcium channel and is involved in B cell proliferation and differentiation. ${ }^{[73]}$ Rituximab is administered i.v. and has a half-life of 22 days. ${ }^{[74]}$ Circulating $\mathrm{B}$ cell numbers stay low for 6-9 months and recover after 12 months. ${ }^{[15]}$ Small proportion of $\mathrm{T}$ and NK cells expresses CD20 and their numbers decrease after rituximab administration for up to 5 months. ${ }^{[75]}$ Another mechanism of action for rituximab was suggested to be the "immune complex decoy hypothesis" (effector cells expressing Fc $\gamma$ receptor are attracted by "decoy sacrificial cellular immune complexes," preventing tissue inflammation and damage). ${ }^{[76]}$ Rituximab down-regulates CD40 and CD80 that are involved in T cell activation $^{[15]}$ and increases the CD4+ regulatory cells (Treg, $\mathrm{Th} 3, \operatorname{Tr} 1)$ at day 30 and $90 .{ }^{[75]}$

In an open-label phase I study, rituximab reduced RR, and new Gd+ and T2 lesion volume in 26 RRMS patients after 72 weeks of follow-up. ${ }^{[77]}$ In a phase II placebo-controlled trial (HERMES), a single course of $1000 \mathrm{mg}$ of i.v. rituximab (days 1 and 15) reduced new $\mathrm{Gd}+$ and $\mathrm{RR}$ compared to placebo (20.3 vs. $40.0 \%$; $p=0.04$ ). In a study of rituximab administered in combination with IFN $\beta, 30$ RRMS patients who had been on an injectable DMT for at least 6 months and had at least one relapse/one $\mathrm{Gd}+$ received four weekly rituximab infusions $\left(375 \mathrm{mg} / \mathrm{m}^{2}\right) .{ }^{[78]}$ At 52 weeks of follow-up, rituximab as an add-on drug significantly impacted MRI primary outcome measures in comparison with baseline measures $(p<0.0001){ }^{[78]}$ Side effects after rituximab infusion include headache, nausea, chills, pyrexia, pharyngeal pain, and fatigue, as reported in the phase II trial. ${ }^{[78]}$

Particular attention should be given to the risk of PML after treatment with rituximab, since more than 50 cases have been reported up to now ( 1 case per 25,000 individuals) of PML in patients with rheumatoid arthritis ${ }^{[79,80]}$ and continued pharmacovigilance is recommended. ${ }^{[80,81]}$

Ocrelizumab is a recombinant humanized antibody that binds to CD20 at a different epitope but partly overlapping with rituximab. ${ }^{[15]}$ Ocrelizumab has a half-life of 23-28 days and induces a rapid $B$ cell depletion after infusion, with a recovery of B cell numbers at 3 months ${ }^{[82,83]}$ A randomized placebo-controlled phase II study of 218 RRMS patients compared two doses of i.v. ocrelizumab (600 mg and $2000 \mathrm{mg}$ ) with placebo and intramuscular interferon beta-1a (30 $\mu \mathrm{g})$ once a week. After 24 weeks, all patients received ocrelizumab $600 \mathrm{mg}$, but the arm initially treated with $2000 \mathrm{mg}$ received $1000 \mathrm{mg}$. Ocrelizumab was administered at weeks 24,48 , and $96 .{ }^{[84]}$ Ocrelizumab (both regimens) had a better 
effect on primary MRI outcomes $(\mathrm{Gd}+$ lesions at weeks 12 and 24) when compared to both placebo and IFN $\beta$ (patients free of $\mathrm{Gd}+$ during 24 weeks: $77 \%$ in $600 \mathrm{mg}$ group, $82 \%$ in $2000 \mathrm{mg}$ group, $48 \%$ in IFN $\beta$, and $35 \%$ in the placebo arm. ${ }^{[84]}$ Currently, a randomized phase III trial (ocrelizumab $600 \mathrm{mg}$ plus placebo-IFN- $\beta 1$ a s.c. vs. IFN- $\beta 1$ a s.c. plus placebo-ocrelizumab every 24 weeks) is ongoing and expected to complete in 2015 (NCT01412333). ${ }^{[15]}$

A phase III trial in rheumatoid arthritis enrolling patients receiving concomitant immunosuppressive medications (such as methotrexate or leflunomide) reported high rates of infections, especially with the $500 \mathrm{mg}$ regimen, and some of those infections resulted in death. ${ }^{[85-87]}$ There were no reported opportunistic infections in the phase II trial. Adverse events reported were similar between the treatment groups; however, there was one death in the $2000 \mathrm{mg}$ arm. ${ }^{[84]}$

Ocrelizumab is less immunogenic due to its humanized profile and, therefore, less likely to cause infusion reactions or induce neutralizing antibody formation. In the MS trials, infusion-related side effects were more frequently associated with the first cycle of administration. ${ }^{[15]}$

Daclizumab is a humanized mouse monoclonal antibody. It antagonizes CD25 which is otherwise up-regulated on activated T cells and allows them to receive the IL-2 signal. Daclizumab has a high specificity for IL-2R, with a capacity of saturating IL-2R for 43 days after a single dose of $2 \mathrm{mg} / \mathrm{kg} \cdot{ }^{[88]}$ Other mechanisms of action for daclizumab have also been suggested. ${ }^{[15]}$ Daclizumab has previously been used to prevent allograft rejection in transplantation and in the treatment of refractory uveitis and adult $\mathrm{T}$ cell leukemia. ${ }^{[15]}$

Two phase II open-label studies of daclizumab in MS suggested a good effectiveness on MRI outcomes (daclizumab added to IFN $\beta$ reduced by $78 \%$ new $\mathrm{Gd}+$ lesions after 15 months of treatment ${ }^{[89]}$ ) and clinical parameters (EDSS)..$^{[90]}$

The 230 patients with active RRMS enrolled in the first randomized phase II trial of daclizumab in MS (CHOICE) received add-on s.c. high- or low-dose daclizumab (2 mg/ $\mathrm{kg}$ every 2 weeks or $1 \mathrm{mg} / \mathrm{kg}$ every 4 weeks, respectively) or placebo for 24 weeks, followed by a further 48 weeks of safety monitoring. ${ }^{[1]}$ Only the high-dose daclizumab decreased the new $\mathrm{Gd}+$ lesions when compared to placebo. The second phase II trial with daclizumab (SELECT) randomized 600 patients with early RRMS to daclizumab (150 or $300 \mathrm{mg}$ ) or placebo with 1 year follow-up. ${ }^{\left[{ }^{22]}\right.}$ Both doses of daclizumab reduced the annualized $\mathrm{RR}(p<0.001)$, while more patients on daclizumab remained relapse-free at 1 year. Besides the clinical parameters, the MRI outcomes were favorable under daclizumab. After the second year of treatment, daclizumab maintained its effects. ${ }^{[15]}$ DECIDE, a double-blind phase III trial comparing IFN- $\beta 1 \mathrm{~b}$ to dacli- zumab in RRMS, is currently ongoing and is due to complete in 2014 (NCT01064401) ${ }^{[15]}$ Rash was more frequent in the daclizumab arm than in the placebo arm (13\% vs. $8 \%)$ in CHOICE trial. ${ }^{[91]}$ Elevation of liver enzymes $>5$ times the normal was reported in daclizumab-treated patients in the SELECT trial. ${ }^{[15]} \mathrm{A}$ case of CNS vasculitis has been reported in a patient who completed a phase II study but continued daclizumab, and a specific immunologic vulnerability was suggested (lack of expansion of CD56bright NK cells). ${ }^{\text {[93] }}$

\section{Conclusion}

First-line DMTs (IFN $\beta$ and GA) are safe, but they are only moderately effective and up to $40 \%$ of MS patients continue to show disease activity on these treatments. ${ }^{[51]}$ A number of new DMTs in advanced development stage have set the stage for redefinition of therapy goals. Freedom from disease, defined as absence of relapses, disability progression, and radiologic evidence of disease activity are therefore perceived as an actual measure of treatment success. ${ }^{[94]}$ Although potentially providing improved efficacy, new therapies for MS may require careful consideration in patient selection and monitoring. The use of other approved DMTs, mitoxantrone, natalizumab, and fingolimod, showed that phase III trials are often insufficient to detect rare but serious adverse events and tend to underestimate their risk due to their short duration and the relatively low numbers of patients treated. The emergence of such adverse events has restricted their use in the light of their risk-benefit profile. This applies to any new agent in MS treatment and is relevant for the challenges that they would face: clinical effectiveness, acceptable side effect profile, and a convenient regimen of administration. Despite meeting all these criteria in licensing trials, those features will also then need to withstand the post-marketing surveillance programs. ${ }^{[94]}$ The early intervention with the best available therapy, a high standard for treatment success, and careful assessment of specific risks are the key to a treatment to significantly improve long-term outcomes for people with MS.

\section{REFERENCES}

1. Compston A, Coles A. Multiple sclerosis. Lancet 2008;372:1502-17.

2. Ogura H, Arima Y, Kamimura D, Murakami M. The gateway theory: How regional neural activation creates a gateway for immune cells via an inflammation amplifier. Biomed J 2013;36:269-73.

3. Stys PK, Zamponi GW, van Minnen J, Geurts JJ. Will the real multiple sclerosis please stand up? Nat Rev Neurosci 2012;13:507-14.

4. Evangelou N. The only way to manage neurodegeneration in MS is to prevent it with effective anti-inflammatory therapy: Yes. Mult Scler 2012;18:1680-1.

5. Polman $\mathrm{CH}$, Reingold SC, Banwell B, Clanet M, Cohen JA, Filippi M, et al. Diagnostic criteria for multiple sclerosis: 2010 
revisions to the McDonald criteria. Ann Neurol 2011;69:292-302.

6. Jeffery DR. Recent advances in treating multiple sclerosis: Efficacy, risks and place in therapy. Ther Adv Chronic Dis 2013;4:45-51.

7. Khatri B, Barkhof F, Comi G, Hartung HP, Kappos L, Montalban X, et al. Oral Fingolimod (FTY720) Reduces the Rate of Relapses That Require Steroid Intervention or Hospitalization Compared with Intramuscular Interferon beta-1a: Results from a Phase III Study (TRANSFORMS) in Multiple Sclerosis. Neurology 2010;74:A552.

8. Kappos L, Radue EW, O'Connor P, Polman C, Hohlfeld R, Calabresi $\mathrm{P}$, et al. A Placebo-Controlled Trial of Oral Fingolimod in Relapsing Multiple Sclerosis. N Engl J Med 2010;362:387-401.

9. Lugaresi A, di Ioia M, Travaglini D, Pietrolongo E, Pucci E, Onofrj M. Risk-benefit considerations in the treatment of relapsing-remitting multiple sclerosis. Neuropsychiatr Dis Treat 2013;9:893-914.

10. Jacobs LD, Beck RW, Simon JH, Kinkel RP, Brownscheidle CM, Murray TJ. Intramuscular interferon beta-1a therapy initiated during a first demyelinating event in multiple sclerosis. CHAMPS Study Group. N Engl J Med 2000;343:898-904.

11. Kappos L, Polman CH, Freedman MS, Edan G, Hartung HP, Miller DH, et al. Treatment with interferon beta- $1 \mathrm{~b}$ delays conversion to clinically definite and McDonald MS in patients with clinically isolated syndromes. Neurology 2006;67:1242-9.

12. Duquette P, Girard M, Despault L, Dubois R, Knobler RL, Lublin FD, et al. Interferon Beta-1b Is Effective in Relapsing-Remitting Multiple-Sclerosis-Clinical-Results of a Multicenter, Randomized, Double-Blind, Placebo-Controlled Trial. Neurology 1993;43:655-61.

13. Jacobs LD, Cookfair DL, Rudick RA, Herndon RM, Richert JR, Salazar AM, et al. Intramuscular interferon beta-1a for disease progression in relapsing multiple sclerosis. The Multiple Sclerosis Collaborative Research Group (MSCRG). Ann Neurol 1996;39:285-94.

14. Randomised double-blind placebo-controlled study of interferon beta- $1 \mathrm{a}$ in relapsing/remitting multiple sclerosis. PRISMS (Prevention of Relapses and Disability by Interferon beta-1a Subcutaneously in Multiple Sclerosis) Study Group. Lancet 1998;352:1498-504.

15. Ali R, Nicholas RS, Muraro PA. Drugs in development for relapsing multiple sclerosis. Drugs 2013;73:625-50.

16. Ziemssen T, Schrempf W. Glatiramer acetate: Mechanisms of action in multiple sclerosis. Int Rev Neurobiol 2007;79:537-70.

17. Johnson KP, Brooks BR, Cohen JA, Ford CC, Goldstein J, Lisak RP, et al. Copolymer 1 reduces relapse rate and improves disability in relapsing-remitting multiple sclerosis: Results of a phase III multicenter, double-blind, placebo-controlled trial. Neurology 2001;57:S16-24.

18. Comi G, Filippi M, Wolinsky JS, Aceta EC. European/Canadian multicenter, double-blind, randomized, placebo-controlled study of the effects of glatiramer acetate on magnetic resonance imaging-measured disease activity and burden in patients with relapsing multiple sclerosis. Ann Neurol 2001;49:290-7.

19. Ford C, Goodman AD, Johnson K, Kachuck N, Lindsey JW, Lisak R, et al. Continuous long-term immunomodulatory therapy in relapsing multiple sclerosis: Results from the 15-year analysis of the US prospective open-label study of glatiramer acetate. Mult Scler 2010;16:342-50.
20. Oh J, Calabresi PA. Emerging injectable therapies for multiple sclerosis. Lancet Neurol 2013;12:1115-26.

21. Polman CH, O’Connor PW, Havrdova E, Hutchinson M, Kappos L, Miller DH, et al. A randomized, placebo-controlled trial of natalizumab for relapsing multiple sclerosis. The $\mathrm{N}$ Engl J Med 2006;354:899-910.

22. Miller DH, Soon D, Fernando KT, MacManus DG, Barker GJ, Yousry TA, et al. MRI outcomes in a placebo-controlled trial of natalizumab in relapsing MS. Neurology 2007;68:1390-401.

23. Rudick RA, Stuart WH, Calabresi PA, Confavreux C, Galetta SL, Radue EW, et al. Natalizumab plus interferon beta-1a for relapsing multiple sclerosis. N Engl J Med 2006;354:911-23.

24. Rommer PS, Zettl UK, Kieseier B, Hartung HP, Menge T, Frohman E, et al. Requirement for safety monitoring for approved MS therapies-An overview. Clin Exp Immunol 2014;175:397-407.

25. Bloomgren G, Richman S, Hotermans C, Subramanyam M, Goelz S, Natarajan A, et al. Risk of natalizumab-associated progressive multifocal leukoencephalopathy. N Engl J Med 2012;366:1870-80.

26. Li JM, Yang Y, Zhu P, Zheng F, Gong FL, Mei YW. Mitoxantrone exerts both cytotoxic and immunoregulatory effects on activated microglial cells. Immunopharmacol Immunotoxicol 2012;34:36-41.

27. Marriott JJ, Miyasaki JM, Gronseth G, O'Connor PW, Therapeutics, Technology Assessment Subcommittee of the American Academy of N. Evidence Report: The efficacy and safety of mitoxantrone (Novantrone) in the treatment of multiple sclerosis: Report of the Therapeutics and Technology Assessment Subcommittee of the American Academy of Neurology. Neurology 2010;74:1463-70.

28. Tanasescu R, Debouverie M, Pittion S, Anxionnat R, Vespignani H. Acute myeloid leukaemia induced by mitoxantrone in a multiple sclerosis patient. J Neurol 2004;251:762-3.

29. Pratt RG, Boehm GA, Kortepeter CM, Racoosin JA. Mitoxantrone treatment of multiple sclerosis: Safety considerations. Neurology 2005;65:1997.

30. Marriott JJ, Miyasaki JM, Gronseth G, O'Connor PW. Evidence Report: The efficacy and safety of mitoxantrone (Novantrone) in the treatment of multiple sclerosis Report of the Therapeutics and Technology Assessment Subcommittee of the American Academy of Neurology. Neurology 2010;74:1463-70.

31. Rivera V, Weinstock-Guttman B, Beagan J, Al-Sabbagh A, Bennett R, Dangond F. Final results from the registry to evaluate novantrone effects in worsening multiple sclerosis study. Mult Scler 2009;15:S254-5.

32. Chun J, Hartung HP. Mechanism of Action of Oral Fingolimod (FTY720) in Multiple Sclerosis. Clin Neuropharmacol 2010;33:91-101

33. Zemann B, Kinzel B, Muller M, Reuschel R, Mechtcheriakova D, Urtz N, et al. Sphingosine kinase type 2 is essential for lymphopenia induced by the immunomodulatory drug FTY720. Blood 2006;107:1454-8.

34. Aktas O, Kury P, Kieseier B, Hartung HP. Fingolimod is a potential novel therapy for multiple sclerosis. Nat Rev Neurol 2010;6:373-82.

35. Mehling M, Lindberg RL, Kuhle J, Vedrine C, Kappos L, Brinkmann V. Oral fingolimod (FTY720) treatment reduces peripheral IL-17-producing TH17 cells in patients with multiple sclerosis. Mult Scler 2008;14:S234-S. 
36. Buzzard KA, Broadley SA, Butzkueven H. What do effective treatments for multiple sclerosis tell us about the molecular mechanisms involved in pathogenesis? Int J Mol Sci 2012;13:12665-709.

37. Mehling M, Kappos L, Derfuss T. Fingolimod for multiple sclerosis: Mechanism of action, clinical outcomes, and future directions. Curr Neurol Neurosci 2011;11:492-7.

38. Cohen J, Barkhof F, Comi G, Hartung HP, Kappos L, Khatri B, et al. Oral Fingolimod (FTY720) Treatment improves the performance of daily activities compared with intramuscular interferon beta-1a: Patient-Reported Indices for Multiple Sclerosis (PRIMUS)-Activities Results from a Phase III Study (TRANSFORMS). Neurology 2010;74:A543-4.

39. Cohen JA, Barkhof F, Comi G, Hartung HP, Khatri BO, Montalban X, et al. Oral fingolimod or intramuscular interferon for relapsing multiple sclerosis. N Engl J Med 2010;362:402-15.

40. Khatri B, Barkhof F, Comi G, Hartung HP, Kappos L, Montalban X, et al. Comparison of fingolimod with interferon beta-1a in relapsing-remitting multiple sclerosis: A randomised extension of the TRANSFORMS study. Lancet Neurol 2011;10:520-9.

41. Miller D, Cree B, Dalton C, Freedman M, Hartung H, Kappos L, et al. Study Design and Baseline Characteristics of the INFORMS Study: Fingolimod in Patients with Primary Progressive Multiple Sclerosis. Neurology; 80(Meeting Abstracts 1): P07.116.

42. EMA.2012. Available from: http://www.emea.europa.eu/ docs/en_GB/document_library/Medicine_QA/2012/04/ WC500125689.pdf EEMAqaaotroGdrnEEHCA. [Last accessed on 2013 Nov 10].

43. Available from: http://www.fda.gov/Drugs/DrugSafety/ucm303192. htm FFdscrrfcmauomsdGfF. [Last accessed on 2013 Nov 10].

44. Tanasescu R, Evangelou N, Constantinescu CS. Role of oral teriflunomide in the management of multiple sclerosis. Neuropsychiatr Dis Treat 2013;9:539-53.

45. O’Connor PW, Li D, Freedman MS, Bar-Or A, Rice GP, Paty DW, et al. A Phase II study of the safety and efficacy of teriflunomide in multiple sclerosis with relapses. Neurology 2006;66:894-900.

46. Freedman MS, Wolinsky JS, Wamil B, Confavreux C, Comi G, Kappos L, et al. Teriflunomide added to interferon-beta in relapsing multiple sclerosis: A randomized phase II trial. Neurology 2012;78:1877-85.

47. Confavreux C, Li DK, Freedman MS, Truffinet P, Benzerdjeb H, Wang D, et al. Long-term follow-up of a phase 2 study of oral teriflunomide in relapsing multiple sclerosis: safety and efficacy results up to 8.5 years. Mult Scler 2012;18:1278-89.

48. O’Connor P, Wolinsky JS, Confavreux C, Comi G, Kappos L, Olsson TP, et al. Randomized trial of oral teriflunomide for relapsing multiple sclerosis. N Engl J Med 2011;365:1293-303.

49. Mrowietz U, Christophers E, Altmeyer P. Treatment of psoriasis with fumaric acid esters: Results of a prospective multicentre study. $\mathrm{Br} \mathrm{J}$ Dermatol 1998;138:456-60.

50. Available from: http://www.ema.europa.eu/ema/index. jsp?curl=pages/medicines/human/medicines/002514/human med_001645.jsp\&mid=WC0b01ac058001d124. [Last accessed on 2014 Feb 15].

51. Available from: http://www.fda.gov/newsevents/newsroom/ pressannouncements/ucm319277.htm. [Last accessed on 2014 Feb 15].
52. Linker RA, Lee DH, Ryan S, van Dam AM, Conrad R, Bista P, et al. Fumaric acid esters exert neuroprotective effects in neuroinflammation via activation of the Nrf2 antioxidant pathway. Brain 2011;134:678-92

53. Kappos L, Gold R, Miller DH, Macmanus DG, Havrdova E, Limmroth V, et al. Efficacy and safety of oral fumarate in patients with relapsing-remitting multiple sclerosis: A multicentre, randomised, double-blind, placebo-controlled phase IIb study. Lancet 2008;372:1463-72.

54. Kappos L, Gold R, Miller DH, MacManus DG, Havrdova E, Limmroth V, et al. Effect of BG-12 on contrast-enhanced lesions in patients with relapsing--remitting multiple sclerosis: Subgroup analyses from the phase 2b study. Mult Scler 2012;18:314-21.

55. Gold R, Kappos L, Arnold DL, Bar-Or A, Giovannoni G, Selmaj K, et al.; DEFINE Study Investigators. Placebo-controlled phase 3 study of oral BG-12 for relapsing multiple sclerosis. N Engl J Med 2012;367:1098-107.

56. Fox RJ, Miller DH, Phillips JT, Hutchinson M, Havrdova E, Kita M, et al. Placebo-controlled phase 3 study of oral BG-12 or glatiramer in multiple sclerosis. N Engl J Med 2012;367:1087-97.

57. Available from: http://www.fda.gov/newsevents/newsroom/ pressannouncements/ucm 345528.htm? source=govdelivery. [Last accessed on $2014 \mathrm{Feb}$ 15].

58. Available from: http://www.ema.europa.eu/ema/index jsp?curl=pages $/$ medicines $/$ human $/$ medicines $/ 002601 /$ human med 001657.jsp\&mid=WC0b01ac058001d124. [Last accessed on 2014 Feb 15]

59. Brueck W, Wegner C. Insight into the mechanism of laquinimod action. J Neurol Sci 2011;306:173-9.

60. Yang HS, Xu LY, Xiao BG, Hedlund G, Link H. Laquinimod (ABR-215062) suppresses the development of experimental autoimmune encephalomyelitis, modulates the Th1/ Th2 balance and induces the Th3 cytokine TGF-beta in Lewis rats. J Neuroimmunol 2004;156:3-9.

61. Thone J, Ellrichmann G, Seubert S, Peruga I, Lee DH, Conrad R, et al. Modulation of autoimmune demyelination by laquinimod via induction of brain-derived neurotrophic factor. Am J Pathol 2012;180:267-74.

62. Polman C, Barkhof F, Sandberg-Wollheim M, Linde A, Nordle O, Nederman T, et al. Treatment with laquinimod reduces development of active MRI lesions in relapsing MS. Neurology 2005;64:987-91.

63. Comi G, Pulizzi A, Rovaris M, Abramsky O, Arbizu T, Boiko A, et al. Effect of laquinimod on MRI-monitored disease activity in patients with relapsing-remitting multiple sclerosis: A multicentre, randomised, double-blind, placebo-controlled phase IIb study. Lancet 2008;371:2085-92

64. Filippi M, Rocca MA, Pagani E, De Stefano N, Jeffery D, Kappos L, et al. Placebo-controlled trial of oral laquinimod in multiple sclerosis: MRI evidence of an effect on brain tissue damage. J Neurol Neurosurg Psychiatry 2013 Sep 12. doi: 10.1136/jnnp-2013-306132. [Epub ahead of print].

65. Comi G, Jeffery D, Kappos L, Montalban X, Boyko A, Rocca MA, et al. Placebo-controlled trial of oral laquinimod for multiple sclerosis. N Engl J Med 2012;366:1000-9.

66. Rommer PS, Stuve O, Goertsches R, Mix E, Zettl UK. Monoclonal antibodies in the therapy of multiple sclerosis: An overview. J Neurol 2008;255 Suppl 6:28-35. 
67. Coles AJ, Cox A, Le Page E, Jones J, Trip SA, Deans J, et al. The window of therapeutic opportunity in multiple sclerosis: Evidence from monoclonal antibody therapy. J Neurol 2006;253:98-108.

68. Investigators CT, Coles AJ, Compston DA, Selmaj KW, Lake SL, Moran S, et al. Alemtuzumab vs. interferon beta-1a in early multiple sclerosis. N Engl J Med 2008;359:1786-801.

69. Coles AJ, Fox E, Vladic A, Gazda SK, Brinar V, Selmaj KW, et al. Alemtuzumab versus interferon beta-1a in early relapsing-remitting multiple sclerosis: Post-hoc and subset analyses of clinical efficacy outcomes. Lancet Neurol 2011;10:338-48.

70. Coles AJ, Fox E, Vladic A, Gazda SK, Brinar V, Selmaj KW, et al. Alemtuzumab more effective than interferon beta-1a at 5-year follow-up of CAMMS223 Clinical Trial. Neurology 2012;78:1069-78.

71. Cohen JA, Coles AJ, Arnold DL, Confavreux C, Fox EJ, Hartung HP, et al. Alemtuzumab versus interferon beta $1 \mathrm{a}$ as first-line treatment for patients with relapsing-remitting multiple sclerosis: A randomised controlled phase 3 trial. Lancet 2012;380:1819-28.

72. Jones JL, Coles AJ. Spotlight on alemtuzumab. Int MS J 2009; 16:77-81.

73. Coles AJ, Compston DA, Selmaj KW, Lake SL, Moran S, Margolin DH, et al. Alemtuzumab vs. interferon beta-1a in early multiple sclerosis. N Engl J Med 2008;359:1786-801.

74. Voso MT, Pantel G, Rutella S, Weis M, D’Alo F, Urbano R, et al. Rituximab reduces the number of peripheral blood B-cells in vitro mainly by effector cell-mediated mechanisms. Haematologica 2002;87:918-25.

75. Kessel A, Rosner I, Toubi E. Rituximab: Beyond simple B cell depletion. Clin Rev Allergy Immunol 2008;34:74-9.

76. Taylor RP, Lindorfer MA. Drug insight: The mechanism of action of rituximab in autoimmune disease--the immune complex decoy hypothesis. Nat Clin Pract Rheumatol 2007;3:86-95.

77. Bar-Or A, Calabresi PA, Arnold D, Markowitz C, Shafer S, Kasper LH, et al. Rituximab in relapsing-remitting multiple sclerosis: A 72-week, open-label, phase I trial. Ann Neurol 2008;63:395-400.

78. Naismith RT, Piccio L, Lyons JA, Lauber J, Tutlam NT, Parks BJ, et al. Rituximab add-on therapy for breakthrough relapsing multiple sclerosis: A 52-week phase II trial. Neurology 2010;74:1860-7.

79. Clifford DB, Ances B, Costello C, Rosen-Schmidt S, Andersson M, Parks D, et al. Rituximab-associated progressive multifocal leukoencephalopathy in rheumatoid arthritis. Arch Neurol 2011;68:1156-64.

80. Carson KR, Evens AM, Richey EA, Habermann TM, Focosi D, Seymour JF, et al. Progressive multifocal leukoencephalopathy after rituximab therapy in HIV-negative patients: A report of 57 cases from the Research on Adverse Drug Events and Reports project. Blood 2009;113:4834-40.

81. Stuve O, Leussink VI, Frohlich R, Hemmer B, Hartung HP, Menge T, et al. Long-term B-lymphocyte depletion with rituximab in patients with relapsing-remitting multiple sclerosis. Arch Neurol 2009;66:259-61.

82. Morschhauser F, Marlton P, Vitolo U, Linden O, Seymour JF, Crump M, et al. Results of a phase I/II study of ocrelizumab, a fully humanized anti-CD20 $\mathrm{mAb}$, in patients with relapsed/refractory follicular lymphoma. Ann Oncol 2010;21:1870-6.

83. Genovese MC, Kaine JL, Lowenstein MB, Del Giudice J, Baldassare A, Schechtman J, et al. Ocrelizumab, a humanized anti-CD20 monoclonal antibody, in the treatment of patients with rheumatoid arthritis: A phase I/II randomized, blinded, placebo-controlled, dose-ranging study. Arthritis Rheum 2008;58:2652-61.

84. Kappos L, Li D, Calabresi PA, O’Connor P, Bar-Or A, Barkhof F, et al. Ocrelizumab in relapsing-remitting multiple sclerosis: A phase 2, randomised, placebo-controlled, multicentre trial. Lancet 2011;378:1779-87.

85. Tak PP, Mease PJ, Genovese MC, Kremer J, Haraoui B, Tanaka Y, et al. Safety and efficacy of ocrelizumab in patients with rheumatoid arthritis and an inadequate response to at least one tumor necrosis factor inhibitor: Results of a forty-eight-week randomized, double-blind, placebo-controlled, parallel-group phase III trial. Arthritis Rheum 2012;64:360-70.

86. Harigai M, Tanaka Y, Maisawa S, Group JA. Safety and efficacy of various dosages of ocrelizumab in Japanese patients with rheumatoid arthritis with an inadequate response to methotrexate therapy: A placebo-controlled double-blind parallel-group study. J Rheumatol 2012;39:486-95.

87. Rigby W, Tony HP, Oelke K, Combe B, Laster A, von Muhlen CA, et al. Safety and efficacy of ocrelizumab in patients with rheumatoid arthritis and an inadequate response to methotrexate: Results of a forty-eight-week randomized, double-blind, placebo-controlled, parallel-group phase III trial. Arthritis Rheum 2012;64:350-9.

88. Bielekova B, Catalfamo M, Reichert-Scrivner S, Packer A, Cerna M, Waldmann TA, et al. Regulatory CD56(bright) natural killer cells mediate immunomodulatory effects of IL-2Ralpha-targeted therapy (daclizumab) in multiple sclerosis. Proc Natl Acad Sci U S A 2006;103:5941-6.

89. Bielekova B, Richert N, Howard T, Blevins G, Markovic-Plese S, McCartin J, et al. Humanized anti-CD25 (daclizumab) inhibits disease activity in multiple sclerosis patients failing to respond to interferon beta. Proc Natl Acad Sci U S A 2004;101:8705-8.

90. Rose JW, Burns JB, Bjorklund J, Klein J, Watt HE, Carlson NG. Daclizumab phase II trial in relapsing and remitting multiple sclerosis: MRI and clinical results. Neurology 2007;69:785-9.

91. Wynn D, Kaufman M, Montalban X, Vollmer T, Simon J, Elkins J, et al. Daclizumab in active relapsing multiple sclerosis (CHOICE study): A phase 2, randomised, double-blind, placebo-controlled, add-on trial with interferon beta. Lancet neurol 2010;9:381-90.

92. Giovannoni G, Gold R, Selmaj K, Havrdova E, Montalban X, Radue EW, et al. A Randomized, Double-Blind, Placebo-Controlled Study To Evaluate the Safety and Efficacy of Daclizumab HYP Monotherapy in Relapsing-Remitting Multiple Sclerosis: Primary Results of the SELECT Trial. Neurology 2012;78.

93. Ohayon J, Oh U, Richert N, Martin J, Vortmeyer A, McFarland H, et al. CNS vasculitis in a patient with MS on daclizumab monotherapy. Neurology 2013;80:453-7.

94. Fox EJ, Rhoades RW. New treatments and treatment goals for patients with relapsing-remitting multiple sclerosis. Curr Opin Neurol 2012;25 Suppl:S11-9. 